\title{
Analysis of the cooling of PV modules with water on their efficiency
}

\author{
Wojciech Luboń $^{1 *}$, Mirosław Janowski ${ }^{1}$, Grzegorz Pełka ${ }^{1}$, Paweł Reczek ${ }^{1}$ \\ ${ }^{1}$ AGH University of Science and Technology, Faculty of Geology, Geophysics and Environmental \\ Protection, A. Mickiewicza 30 Ave, 30-059 Krakow, Poland
}

\begin{abstract}
The article presents the results of research on the efficiency of photovoltaic modules cooled by water. The purpose of the experiment was to improve the working conditions of the solar cells. Lowering the cell temperature increases the power generated by the device. The decrease in the temperature of the PV module was obtained by pouring water on the upper surface of the cells, as rain imitation or a water film. The power of the cooled and non-cooled devices were compared. The best results were achieved by cooling cells with a water film since there were no water splashes. The continuous cooling of cells surface causes a $20 \%$ increase of device's power. During the test, the non-cooled module reached the maximum power of $172 \mathrm{~W}$, while the cooled one - $205 \mathrm{~W}$. Cooling the module resulted in an increase in power by $33 \mathrm{~W}$. In addition, the temperature of the cells dropped to almost $25^{\circ} \mathrm{C}$. At this time, the temperature of the non-cooled module was $45^{\circ} \mathrm{C}$. The presented solution may be an interesting proposition for small installations. The solution can also be an alternative for cleaning the modules due to the improvement in the power of the module after the test in terms of their power before.
\end{abstract}

\section{Introduction}

In recent years, a significant development of the technology of converting solar energy into useful energy has been observed [1]. Photovoltaic modules that allow the direct production of electricity are more commonly used, while new technological solutions affect the increase in the efficiency of devices [2]. The power generated from the unit surface of solar generators increases, however, a lot of already installed PV modulesare working. A side effect of their work is a slight but unavoidable degradation. The study was conducted in the field centre of the university - AGH-UST Educational and Research Laboratory of Renewable Energy Sources and Energy Saving in Miękinia near Krzeszowice, where the installation with different PV modules was constructed. The laboratory offered substantive and technical support that allowed the experiment to be conducted.

\footnotetext{
* Corresponding author: lubon@agh.edu.pl
} 


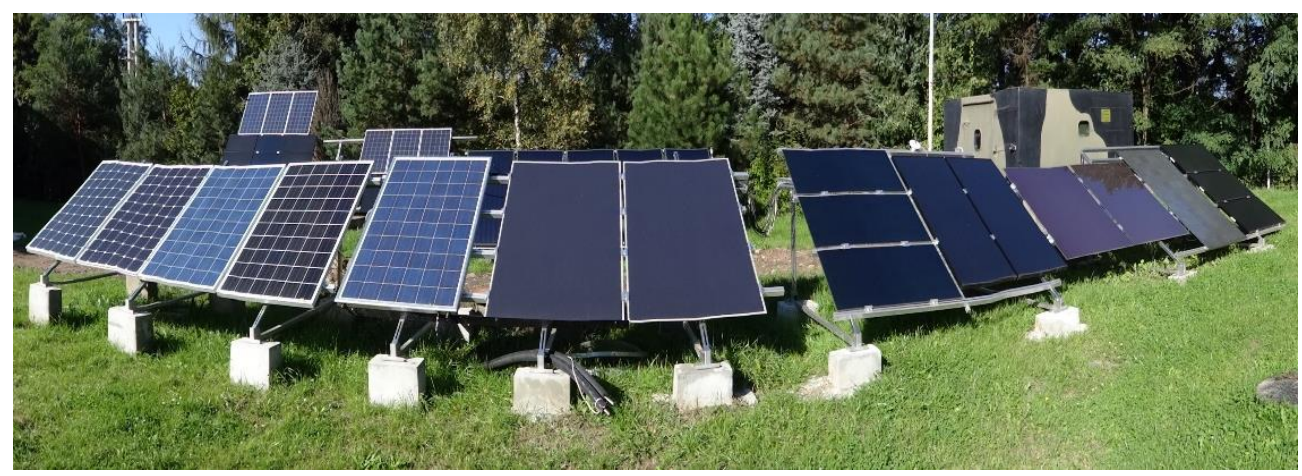

Fig. 1. The installation with different PV modules.

\section{Aim}

The purpose of the research and analyses was to maximize the energy yields achieved during the operation of the PV panels. It is important to pay attention to the discrepancy between the panel's actual power during its operation in full sun and the nominal power, given in $\mathrm{kWp}$, of the unit and which is a standardized parameter for all solar modules [3]. The nominal power of the PV module is achieved in STC conditions by laboratory testing, in which the most important parameters determined are:

- $\quad$ solar radiation intensity - $1000 \mathrm{~W} / \mathrm{m} 2$

- temperature of photovoltaic cells exposed to light $-25^{\circ} \mathrm{C}$

- $\quad$ spectrum of solar radiation - AM 1.5

During the operation of the PV installation in real conditions, a low temperature (like in STC conditions) of the cells is extremely difficult to achieve, especially when the device generates electricity at full intensity of solar radiation. The possibility of such conditions occurs during winter, when the outside temperature is very low and solar radiation is high (e.g. in the upper parts of the mountains). However, the periods in which the photovoltaic installation generates the largest amount of energy and the highest powers are characterized by high values of solar radiation, but also an ambient temperature that makes it impossible to maintain a low test temperature value of PV panels [4]. The effect of sunlight on the dark blue or black surface (a relatively high thermal radiation absorption coefficient) of the device determines the increase of its temperature. PV modules are made from semiconductors, which have changing resistance depending on temperature - when the temperature increase, so does resistance and this leads to the decrease in voltage generated by the cell. While the voltage drops noticeably with temperature increase, the generated current only increases slightly. The power of the photovoltaic module is expressed as the product of instantaneous current and voltage values of the generated electric current, whereby the voltage parameter has a much more significant meaning [5]. Therefore, it is important to take into consideration changes in ambient temperatures during their operation when photovoltaic installations are designed.

The main aim of the research was to decrease the temperature of photovoltaic cells during the generation of electricity, which was supposed to lead to an increase in the power of solar generators. To reduce the temperature of the device, it was decided to use water. Two solutions were used - imitation of rain (Fig.2.) and water film (Fig. 3), being a thin layer of water flowing on the surface of the module, like a river in a wide shallow riverbed. 


\section{ICORES 2019}

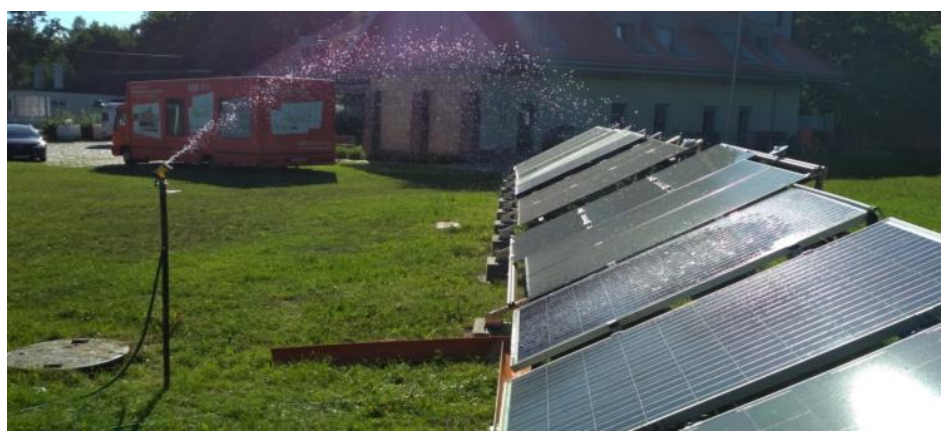

Fig. 2. Research stand with cooling by imitation of rain

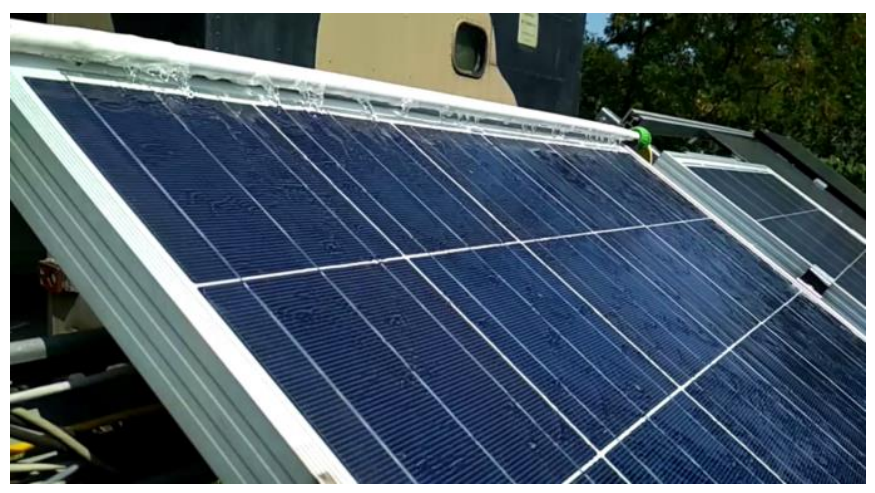

Fig. 3. Research stand with cooling by water film

\section{Research}

The research was conducted using $240 \mathrm{Wp}$ polycrystalline solar PV modules (GermanSolar GSP5 240-SI60), connected to an electrical grid with 220 Watt microinverters (ReneSola Micro Replus-250). The stand included a pair of PV modules, one of which became a reference device and the other being a cooled generator. The measuring system consisted of a DC network parameters gauge, which read the instantaneous parameters of the electrical voltage, current and power of each PV module. The intensity of solar radiation was measured using a pyranometer. All data was saved on a computer using the mLog program. 


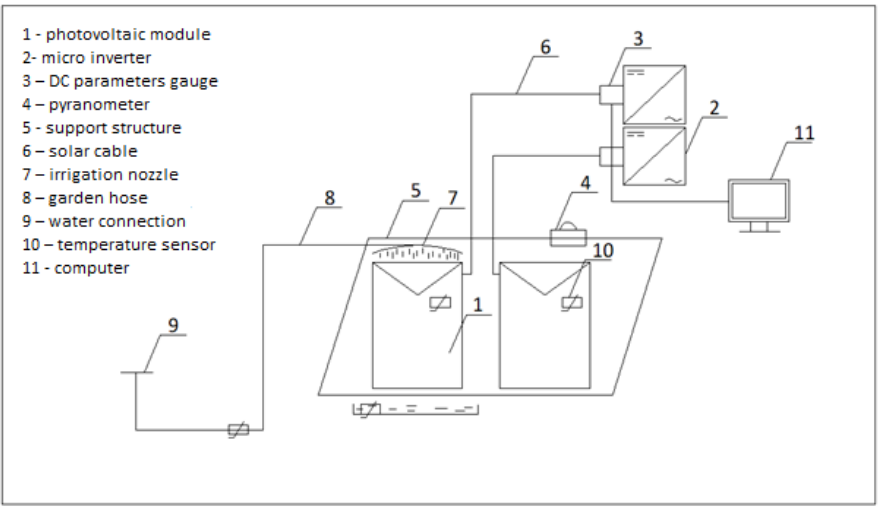

Fig. 4. Scheme of the test stand

The water pouring tests allowed the verification of the efficiency of the cooling process. It transpired that for the effective removal of heat, the surface of the module had to be splashed with water for at least 1 minute. The research conducted in August 2018 showed that the reflection of sunlight from the module surfaces caused by the water is not significant enough to noticeably limit the amount of solar energy supplied to the devices. Therefore, measurements with constant water supply to the surface of the module proved to be the most effective. During 30 minutes of testing, the solar generator was cooled by imitation of rain for the first 15 minutes, and for the next 15 minutes by means of a water film. This test also allowed the comparison of the efficiency of both cooling systems in very similar conditions, in order to choose the optimal solution.

During the test, favorable atmospheric conditions occurred. The ambient temperature was $28^{\circ} \mathrm{C}$ with slight cloud cover, which caused the sun to be covered twice during the experiment. Wind conditions were moderate, characterized by an average wind speed of 0.7 $\mathrm{m} / \mathrm{s}$, with a temporary maximum value of $5.8 \mathrm{~m} / \mathrm{s}$. The moments in which clouds shading the modules are visible in the graphs in Fig. 5. Especially at the beginning of the research, the cloud cover was so extensive that the value of solar irradiance from the level of 800-900 $\mathrm{W} / \mathrm{m} 2$ dropped to almost $200 \mathrm{~W} / \mathrm{m} 2$, which clearly influenced the instantaneous power of the devices and the impact of cooling.

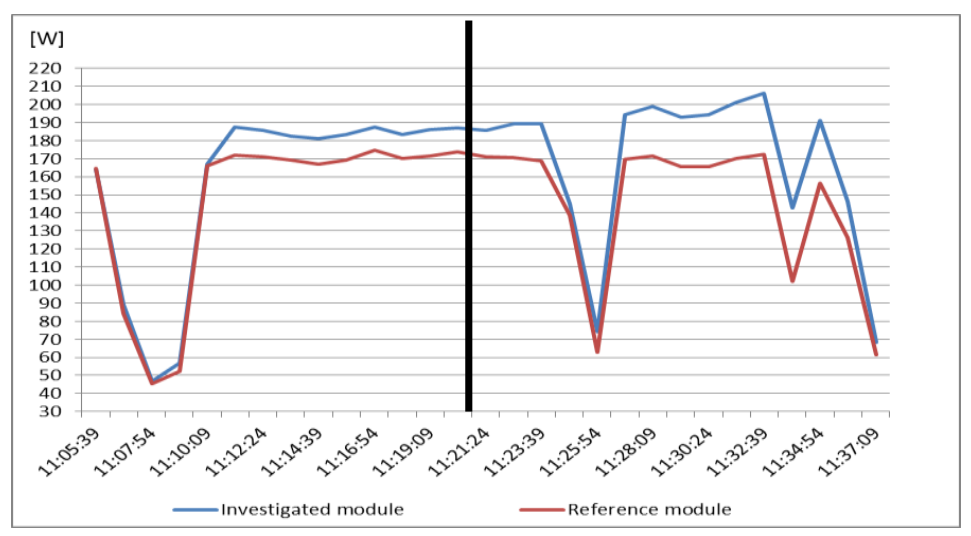

Fig. 5. Power of PV modules during the test 
The graph shown in Fig. 5 clearly confirms this change. However, once the solar conditions stabilize, the effect of cooling starts to be noticeable and has a clear influence on the improvement of the tested module's power compared with the power of reference module. The use of rain imitation in these atmospheric conditions cause meant that $15 \mathrm{~W}$ of power was obtained in the chilled device. The attached chart shows the time from 11.05:39 to 11.21:30. Then, the cooling system changed and water in the form of a water film starts to flow. The cooling effect is immediately noticeable. In the graph (Fig. 5), the power lines of both devices clearly start to diverge. Then, the momentary cloudiness causes the power of solar generators to fall by almost the same value but once the favorable conditions return, the excess power in the cooled module gradually increases. It ranges from $20 \mathrm{~W}$ at the beginning of the water film to over $30 \mathrm{~W}$ at its peak.

\section{Conclusions}

This cooling system may be an interesting solution for increasing the efficiency of the installation. It may be used in existing installations, where increasing nominal power can be complicated. The cooling system can be also used in newly built installations to improve their efficiency. An additional beneficial factor resulting from the use of PV module cooling is the fact that after the tests, the tested module was not covered with any dust, as was seen in the comparative module. After equalizing the temperature of both modules after the tests, a minimally higher power was generated by the module whose surface was free from pollution.

Acknowledgments:

The paper was prepared under AGH-UST statutory research grant No. 11.11.140.031.

\section{References}

1. K. Menoufi. Dust accumulation on the surface of photovoltaic panels: Introducing the Photovoltaic Soiling Index (PVSI), Sustainability (Switzerland), 9(6).

2. GK. Singh. Solar power generation by PV (photovoltaic) technology: A review. Energy. 53:1-13 (2013).

3. J. Kurnik, J, M. Jankovec, K. Brecl, M. Topic. Outdoor testing of PV module temperature and performance under different mounting and operational conditions. Solar Energy Materials and Solar Cells. 95:373-376. (2011)

4. E. Klugmann-Radziemska. Efekty termiczne konwersji energii w krzemowych ogniwach fotowoltaicznych, [monograph] Wydawnictwo Politechniki Gdańskiej, Gdańsk (2005)

5. W. Luboń, G. Pełka, K. Marszałek, A. Małek, Performance analysis of crystalline silicon and CIGS photovoltaic modules in outdoor measurement. Ecological Chemistry and Engineering. vol. 24 nr 4, s. 539-549 (2017) 